\title{
Free LNAPL Volume Estimation by Pancake Model and Vertical Equilibrium Model: Comparison of Results, Limitations, and Critical Points
}

\author{
Eleonora Frollini ${ }^{1,2}$ and Marco Petitta $\mathbb{D}^{1,2}$ \\ ${ }^{1}$ IRSA-CNR, Via Salaria Km 29,300, 00015 Monterotondo, Italy \\ ${ }^{2}$ Department of Earth Sciences, Sapienza University of Rome, Piazzale Aldo Moro 5, 00185 Rome, Italy \\ Correspondence should be addressed to Marco Petitta; marco.petitta@uniromal.it
}

Received 4 December 2017; Revised 19 February 2018; Accepted 20 March 2018; Published 29 April 2018

Academic Editor: Daniele Pedretti

Copyright (C) 2018 Eleonora Frollini and Marco Petitta. This is an open access article distributed under the Creative Commons Attribution License, which permits unrestricted use, distribution, and reproduction in any medium, provided the original work is properly cited.

\begin{abstract}
Light nonaqueous phase liquids (LNAPLs), due to their low solubility, dissolve slowly, acting as a long-term source of water contamination, and consequently they represent an important environmental issue. In the subsoil, more than $99 \%$ of spilled LNAPL remains as adsorbed and free phase; therefore, the volume estimation of free phase, obtained in this case through two different conceptual models (Pancake Model and Vertical Equilibrium Model), is considered a fundamental step for a correct site remediation. According to the first model, the LNAPL floating on the water table and its saturation is up to $100 \%$; instead, according to the second one, the LNAPL can penetrate below the water table and the coexistence of LNAPL, water, and air in the pore fraction, leads to a lower LNAPL saturation, variable with the depth. Actually, in subsoil LNAPL and water saturations vary with depth due to the influence of capillarity, leading to the inaccuracy of Pancake Model assumption. Despite the evident limitation of Pancake Model, both models were applied, coupled with area calculations with Thiessen polygons and grid at regular mesh, to roughly estimate the free LNAPL volume existing in a contaminated site. The volume estimation carried out, considering the LNAPL type and its features, the soil type, and relative effective porosity, provides estimates of volumes having differences up to thousands of cubic meters. The results analysis shows that this estimation has several critical points such as area definition and the lack of sitespecific data (e.g., porosity). Indeed, the sensitivity analysis for porosity shows that a reduction of this parameter provides a $20 \%$ reduction of estimated volume.
\end{abstract}

\section{Introduction}

The occurrence of LNAPLs (light nonaqueous phase liquids) in the subsoil can be due to leaking underground storage tanks, improper surface applications, inadvertent spills, and abusive waste disposal. These compounds, due to their chemical-physical properties, represent potential long-term sources of contamination [1]. In addition, because of their typically high toxicity, small amounts of LNAPLs can contaminate very large volumes of soil and groundwater, producing detrimental effects on both human health and ecological environment $[1,2]$. For this reason, contaminated groundwater may not be used for human and animal consumption and for irrigation purpose [3].
In the vadose zone, the migration of LNAPL is ruled by gravity, capillary forces, residual soil retention capacity, and entry pressure [4-6]. Indeed, immediately following the release, if capillary forces exceed the residual soil retention capacity, the LNAPL migrates downwards under the influence of gravity until reaching the water table. Once the LNAPL is in contact with the capillary fringe, when it reaches and exceeds the entry pressure (inversely related to the pore throat radius), it can displace water and penetrate the water table; otherwise, it starts spreading laterally [4-6].

The above-mentioned key factors govern also the LNAPL partitioning in the residual phase (adsorbed to solids particles due to capillary forces) and free phase (a liquid separated phase immiscible in water) that represent the $99 \%$ of LNAPL 
in the subsoil $[1,7,8]$. The widespread attendance of free phase in the subsoil and its capability to create mobile dissolved and vapour phases that represent dominant pathways for risk to ecosystem and human health [9] lead to the necessity to estimate the free LNAPL volume in order to recover it and remediate the contaminated site.

With time, the different conceptual models developed to estimate saturations of LNAPL in the subsoil and free LNAPL specific volume are described in many papers (e.g., [10-18]). Even now, LNAPL dynamics are studied through numerical modelling, leading to a quick developing of this field science (e.g., [19-26]).

The most known and applied models by practitioners and regulators, due to their simplify applicability, are Pancake Model and Vertical Equilibrium Model, both from the family of analytical models.

In this paper, the volume estimations of supernatant present in a contaminated site are described, quantified using the two different conceptual models mentioned above: Pancake Model and Vertical Equilibrium Model. The aim of this paper is to verify the accuracy and the differences in estimation due to the adoption of different simple methods for LNAPL thickness and for spatial grids. A correct initial estimation of these volumes has a fundamental value for practical actions, as monitoring activities and remediation plans, and it can be considered as a priority step for further detailed evaluations, aimed to reduce the inaccuracy of initial estimation, to be conducted by more sophisticated models, based on costly monitoring activities. In addition, we intend to provide a contribution to the description of tools and steps necessary for the free volume estimation, also highlighting the possible critical points in the adopted procedures.

\section{Site Description}

The study area is a contaminated site, characterized by a diffused contamination by LNAPLs in free and dissolved phase, chlorinated solvents, agricultural fertilizers, and heavy metals [27]. Its location cannot be explicitly indicated for privacy reasons. Since 2002, in order to solve the environmental problem, the site has been undergoing remediation through a horizontal flow barrier and a hydraulic barrier (Figure 1). The horizontal flow barrier, by a vertical bentonite wall, penetrates the full thickness of the shallow aquifer and part of the underlying aquitard in the eastern and central part of the site [28]. The hydraulic barrier currently consists of 85 pumping wells and 20 hot-spot monitoring wells leading to an extraction rate of more than $5000 \mathrm{~m}^{3} / \mathrm{d}$. Water table changes due to natural fluctuations and pumping activities are monthly recorded in more than 350 monitoring wells.

2.1. Geological and Hydrogeological Framework. Four different geological units (Pleistocene - Holocene) occur in the study area: sands unit, with an average thickness of about 25-30 m; clay-silty unit, with a variable thickness from $15 \mathrm{~m}$ to $35 \mathrm{~m}$; and sands and gravel unit with variable thickness due the underlying unit of grey clay. An unconformity, formed during the last glacial period (Würm), separates the two last units. The four geological units coincide with four major hydrostratigraphic units: (1) shallow aquifer, (2) aquitard, (3) deep aquifer, and (4) aquiclude $[27,28]$. The unconfined shallow aquifer, characterized by an average hydraulic conductivity of about $2 * 10^{-4} \mathrm{~m} / \mathrm{s}$, is contaminated and subjected to remediation.

Based on stratigraphic logs, it is possible to identify the two main lithologies constituting the shallow aquifer intercepted by the monitoring wells: (1) sands, (2) sands, and silty sands (Figure 2).

2.2. LNAPL Spatial Distribution, Measured Thicknesses, and Subsurface Conditions. Free LNAPL, characterized by different composition, has been detected in several monitoring wells located mainly in the central area of the study site (Figure 2). The main kinds of LNAPL are gasoline (more of $70 \%$ of $\mathrm{C}_{6}-\mathrm{C}_{9}$ ), diesel (more of $70 \%$ of $\mathrm{C}_{10}-\mathrm{C}_{30}$ ), and mixture of gasoline and diesel. In June 2013, most of monitoring wells with supernatant are characterized by diesel (54\% of the total points), mainly distributed in the central area and in the western side. Monitoring wells with gasoline and mixtures of gasoline and diesel are located in the western side too (Figure 2). However, this spatial distribution was not steady with time; indeed, the monitoring surveys carried out show a variation with time of LNAPL composition.

The measured product thickness, in June 2013, varies from few centimetres to $1.15 \mathrm{~m}$. In addition, these thicknesses show a nonhomogeneous distribution, since it is possible to observe monitoring wells with significant thickness of supernatant close to monitoring points with negligible occurrence of LNAPL (Figure 3).

Analysis of hydrographs and Diagnostic Gauge Plots (DGP) shows unconfined supernatant, without a confining layer preventing LNAPL movement upward (Figure 4). In fact, the hydrographs display an inverse correlation between the measured product thickness and the groundwater level. In the DGP, there is also an inverse correlation between measured product thickness and air/oil interface (AOI), oil/water interface (OWI), and corrected groundwater surface (CGWS) [29], which is obtained by [30]

$$
\mathrm{CGWS}=\mathrm{GWS}+(\mathrm{PT} * \rho),
$$

where GWS ( $m$ a.s.l.) is the measured groundwater level, PT $(\mathrm{m})$ is the measured product thickness, and $\rho$ is the LNAPL density, here considered equal to $0.8 \mathrm{~g} / \mathrm{cm}^{3}$, as average value calculated by the measured densities of the LNAPL collected samples. The LNAPL subsurface conditions are important, because the Vertical Equilibrium Model (that is one of the two models used for the volume estimation and described in the following paragraphs) assumes that the apparent product thickness is equal to the real thickness if the supernatant is unconfined; instead it is higher if the LNAPL is confined [31].

The above-described LNAPL spatial distribution, measured thicknesses, and subsurface conditions refer only to monitoring wells. Pumping wells values have been considered less reliable for a correct volume estimation, since the withdrawal influences the measured product thickness and the 


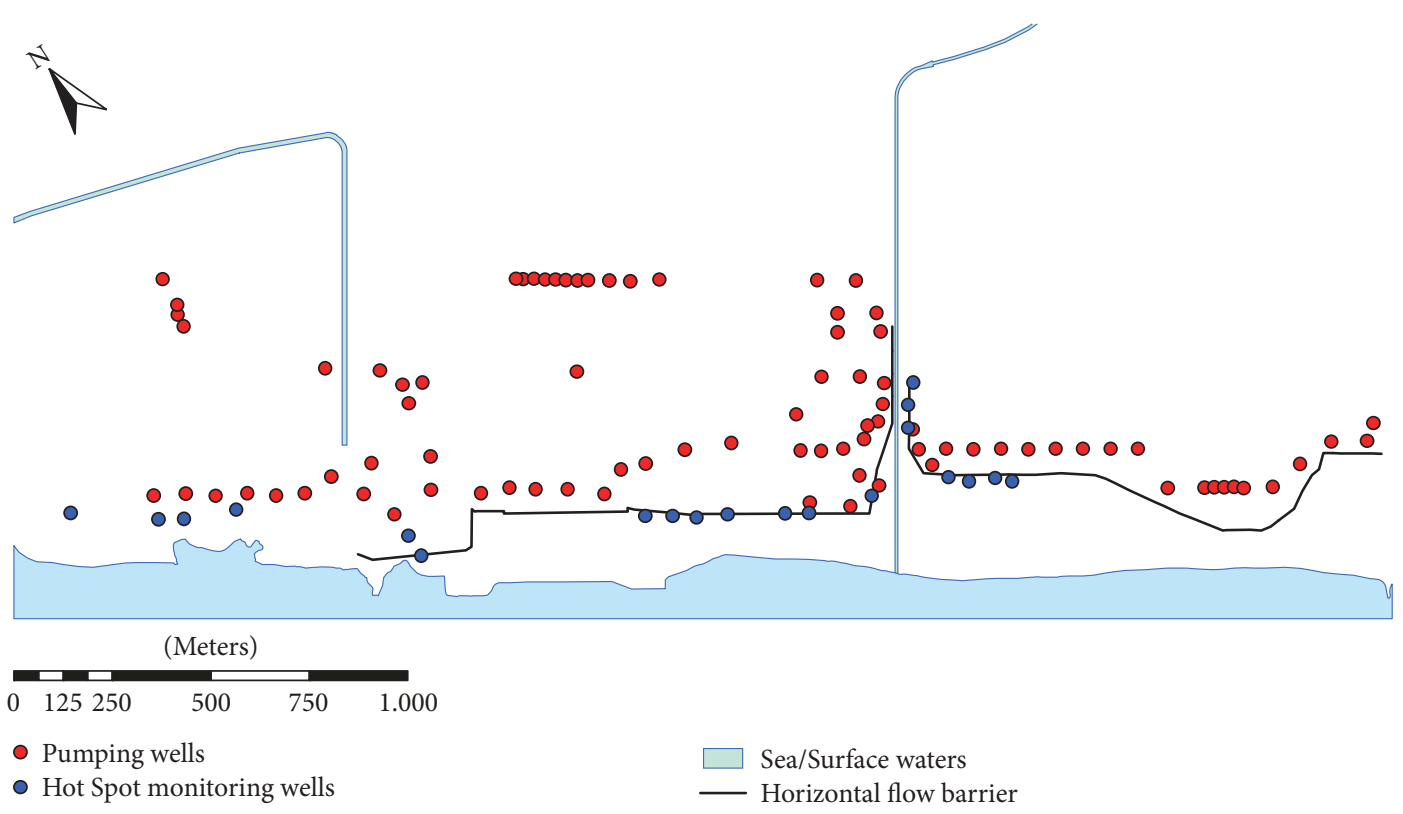

FIGURE 1: Horizontal flow barrier and hydraulic barrier of the study site. Pumping wells in red and hot-spot monitoring wells in blue.

LNAPL characteristics, because of the coexistence of mixture of different LNAPL types in the wells.

\section{Materials and Methods}

The free LNAPL volume estimation can be obtained applying two different conceptual models: Pancake Model and Vertical Equilibrium Model. Both models, which essentially differ for their assumptions about the product distribution in the subsoil, have been applied in this paper.

3.1. Pancake Model. According to the Pancake Model, once LNAPL reaches the water table, due to its immiscibility in water, it remains suspended on the capillary fringe above the water table as a buoyant pool with uniform, constant, and complete saturation $[4,6,32,33]$ (although sometimes a saturation lower than 1 is assumed [10]). Despite the physical limitation of this approach, it continues to be adopted, at least in Italy, for LNAPL volume estimation in subsoil. The thickness measured in the monitoring well is usually considered as an apparent thickness $[11,34,35]$. The difference between apparent and real thickness is due to the absence of the capillary fringe in the monitoring well. In fact, this absence conducts a lower level of water table in the well and consequently free product flows more easily in the monitoring well, creating an exaggerated thickness of supernatant [36]. In addition, the weight of free phase depresses above the water table in the monitoring well, further facilitating the flow of free product in the well. Other key factors that influence the difference between apparent and real thickness are LNAPL density, volume of LNAPL release, and grain size distribution of the aquifer [35].

Since according to the Pancake Model there is a difference between the apparent and the real thickness, it is mandatory to correct the thickness measured in the monitoring well. There are different ways to correct this measure such as empirical factors (e.g., four according to [12]) or factors derived by field tests (recharge test and baildown test).

In the studied contaminated site, baildown tests have been used to calculate the exaggeration factor, according to Gruszczenski [34] or Hughes et al. [36], in order to estimate the real thickness of free phase in the aquifer. In the monitoring wells where baildown tests were not carried out, an average exaggeration factor derived by available data is considered. The applied average exaggeration factor is obtained considering the type of supernatant present in the monitoring wells; in other words, the exaggeration factor applied to monitoring wells not undergoing baildown tests and characterized by diesel is obtained by the average of exaggeration factors derived by baildown tests realized in the monitoring wells with diesel. The same procedure has been performed for the other LNAPL types. The apparent measured thickness and the exaggeration factor (ranging from 3 to 13.5) allow calculating the real thickness in every monitoring point. Multiplying the real thickness for the effective porosity, set as 0.25 for sands [37] and as 0.20 for sands and silty sands [38], it is possible to obtain the specific thickness. From the specific thickness, the volume of free LNAPL present in the subsoil has been derived, multiplying the specific thickness for a linked area, achieved using two different methods: Thiessen polygons and grid at regular square mesh $(100 \mathrm{~m} \times 100 \mathrm{~m}$ and $200 \mathrm{~m} \times$ $200 \mathrm{~m}$ ) [7]. The mesh size is due to the available data, chosen to have at least one or more monitoring wells in the same square cell. Thiessen polygons have been built by ArcGIS (distributed by ESRI Inc.) considering all the monitoring wells located in the site; therefore, every monitoring point is associated with a Thiessen polygon. The product volume of each Thiessen polygon, achieved multiplying the area of Thiessen polygon for the specific thickness of the associated point, 

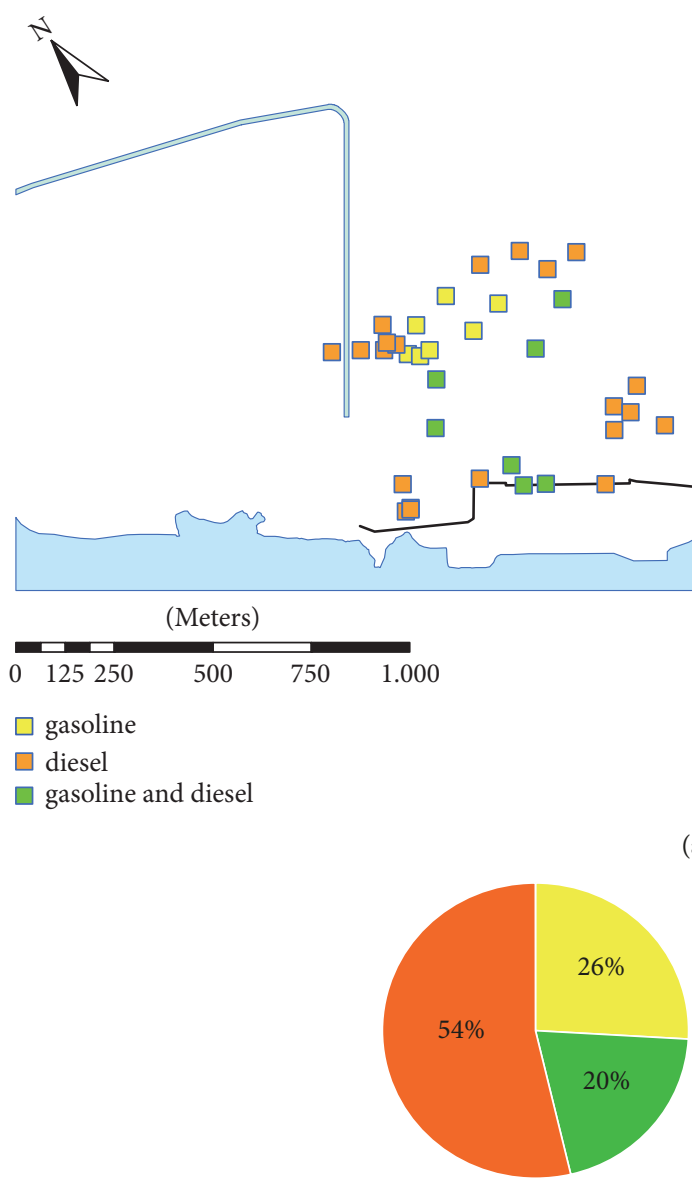

Sea/Surface waters

— Horizontal flow barrier

(a)

gasoline
gasoline and diesel
diesel

(b)

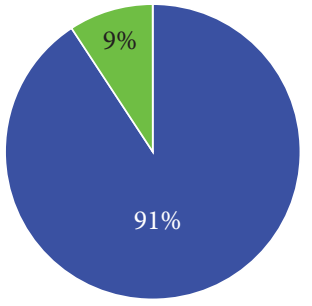

sands

sands and silty sands

(c)

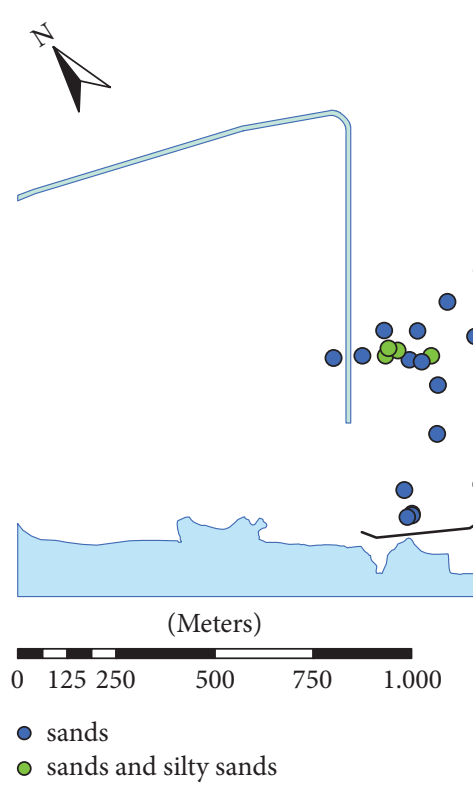

Sea/Surface waters

Horizontal flow barrier

(d)

FIGURE 2: (a) Distribution map of LNAPL types present in monitoring wells at June 2013; (b) percentage of LNAPL types present in monitoring wells at June 2013; (c) percentage of different soil types found in the contaminated monitoring wells; (d) distribution map of soil type found in the contaminated monitoring wells. 


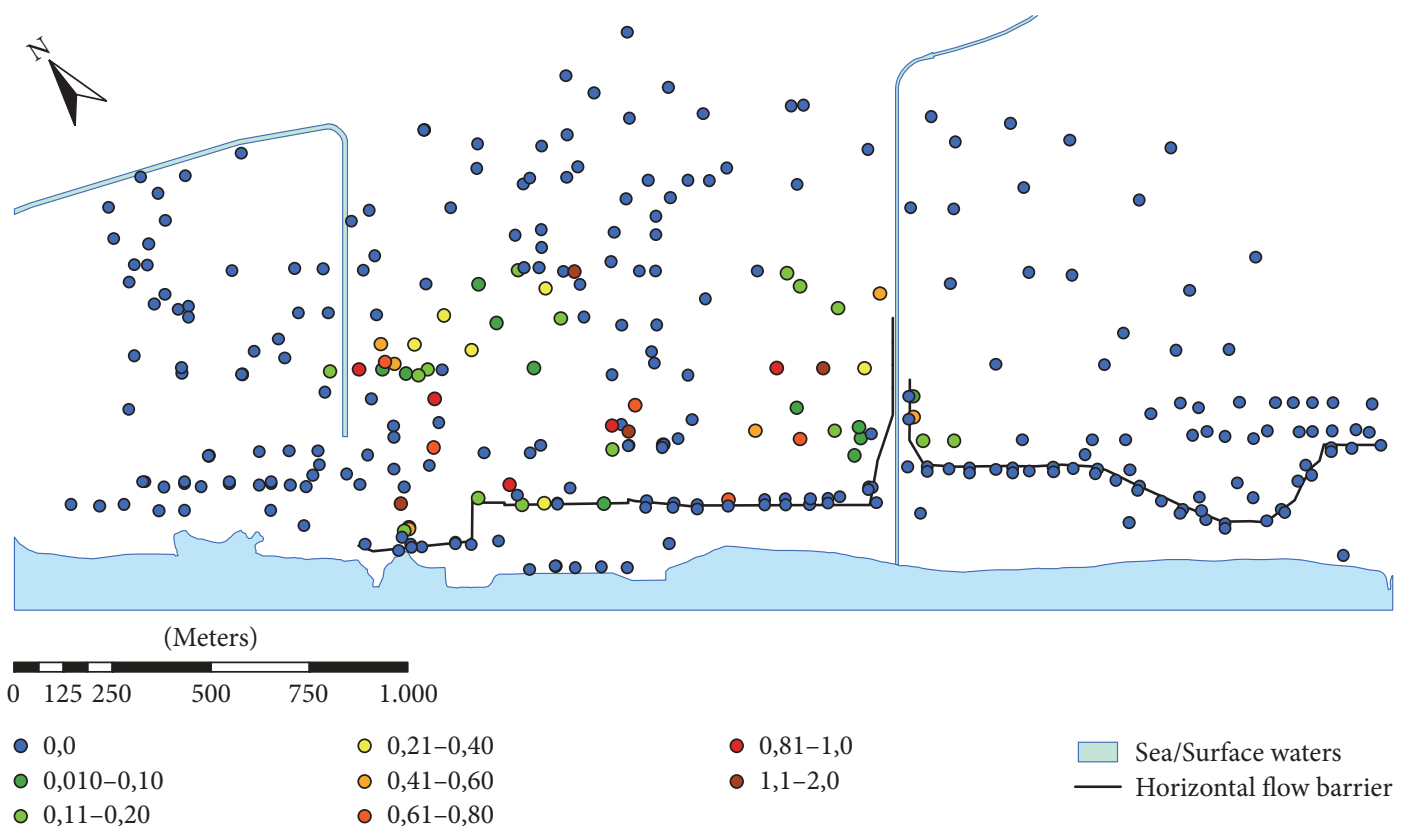

FIGURE 3: Distribution map of free LNAPL thickness (m) measured in the monitoring wells at June 2013.

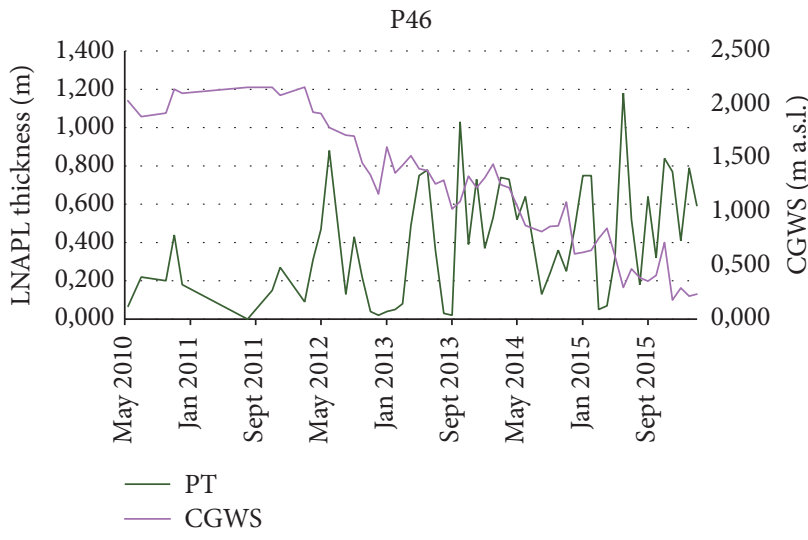

LNAPL thickness (m)
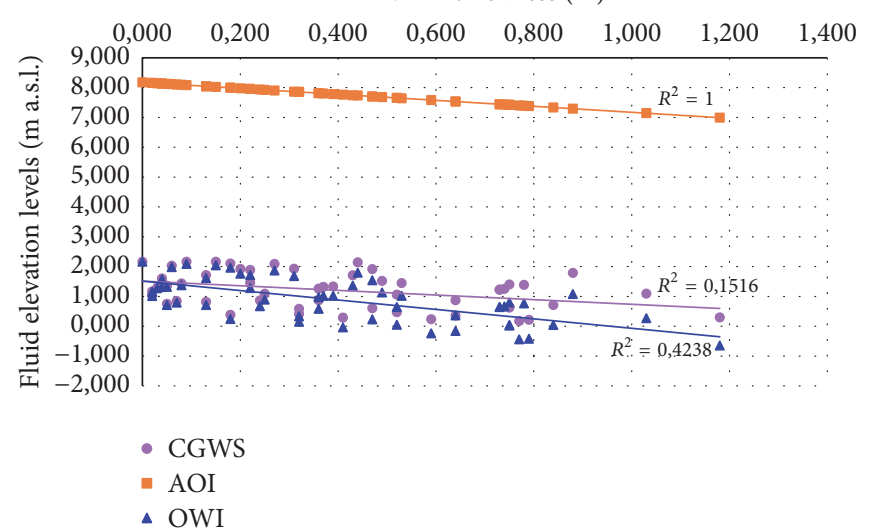

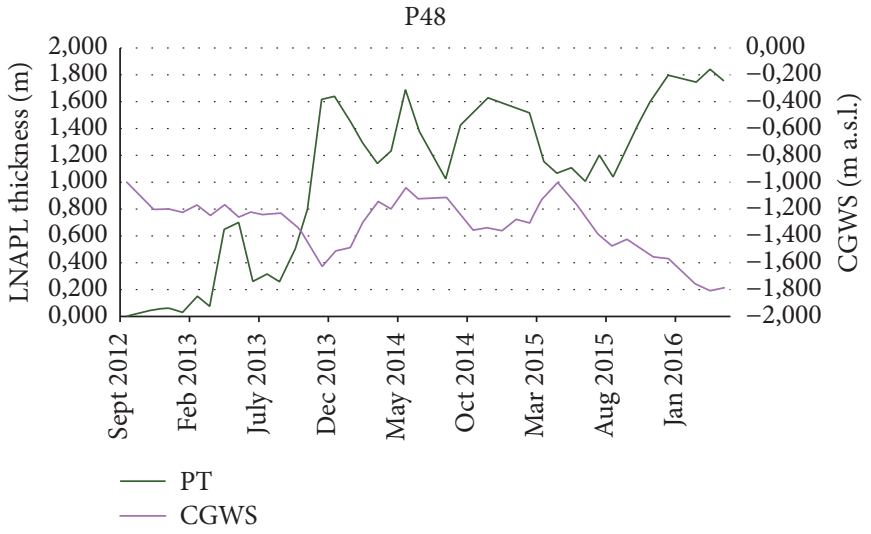

LNAPL thickness (m)

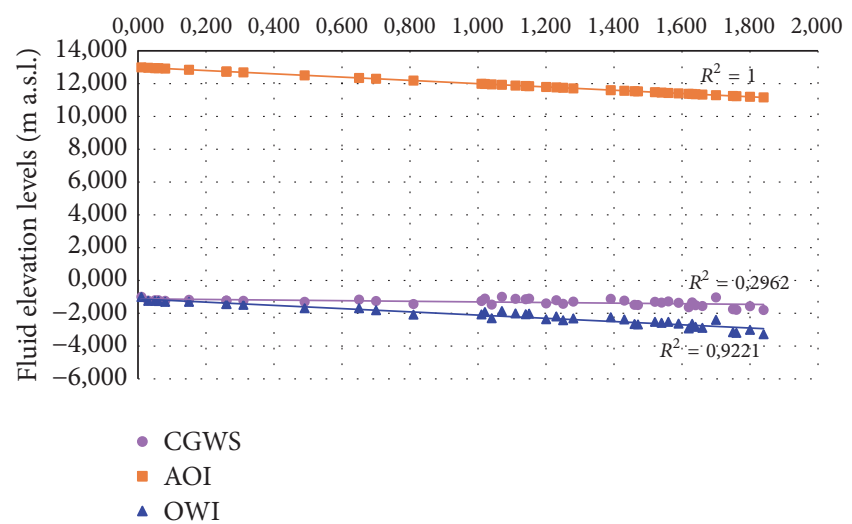

FIGURE 4: Hydrographs and diagnostic gauge plots of P46 and P48, indicating the product thickness (PT), the corrected water table level (CGWS), the air/oil interface (AOI), and the oil/water interface (OWI). 
TABLE 1: LNAPL input parameters in LDRM for specific volume estimation.

\begin{tabular}{lccc}
\hline & Diesel & Gasoline & Gasoline and diesel \\
\hline LNAPL density $(\mathrm{gm} / \mathrm{cc})$ & 0.878 & 0.738 & 0.785 \\
LNAPL viscosity $(\mathrm{cp})$ & 4.882 & 0.301 & 0.707 \\
Air/water surface tension $($ dynes/cm) & 72.74 & 57.90 & 50.83 \\
Air/LNAPL surface tension $($ dynes/cm) & 27.07 & 24.70 & 25.86 \\
LNAPL/water surface tension $($ dynes/cm) & 29.60 & 13.60 & 14.06 \\
\hline
\end{tabular}

has been summed to obtain the total product volume in the subsoil. Conversely, by the method based on grid at regular square mesh, an average specific thickness has been associated with every mesh considering the monitoring wells located in the mesh. The obtained average specific thickness is then multiplied for the mesh area for each cell obtaining the total product volume present in the subsoil.

In order to understand the influence of Thiessen polygon mesh, new polygons have been drawn using not only the monitoring wells located in the site, but also the pumping wells. The new Thiessen polygons have been associated with the specific thicknesses obtained for each monitoring points. In this case, the specific thickness has been calculated considering the same effective porosity value and the same average exaggeration factor in the monitoring points where baildown test data were not available. The use of the averaged exaggeration factor is necessary because the pumping wells show a mixing of the different types of LNAPL that prevent the identification of a characteristic product composition.

3.2. Vertical Equilibrium Model. The Vertical Equilibrium Model, applicable when the release of contaminant is ceased, assumes that LNAPL can penetrate below the water table and it does not create a discrete layer floating on it [13]. According to it, the LNAPL, penetrating below the water table, occupies the pore fraction in coexistence with water and air. The presence of these other fluids leads the LNAPL to have a saturation less than $100 \%$ and variable with the depth $[13,14]$. The shape of LNAPL saturation profiles can be regular (shark fin) for homogeneous aquifer or irregular for the heterogeneous ones. Hence, according to the Vertical Equilibrium Model, the relationship between the LNAPL thickness in the monitoring well and its specific volume in the aquifer derives from the capillary properties of the soil and the LNAPL characteristics that influence the saturation profiles. Usually, given a certain thickness in the well, the specific volume will be lower if a finer material constitutes the aquifer [13,14]. Therefore, the Vertical Equilibrium Model requires the knowledge of the saturation profiles to calculate the specific volume. There are different ways to obtain these curves. For instance, they can be estimated using empirical approaches (measuring saturation in core samples), by analytical modelling or with software as LDRM (LNAPL Distribution and Recovery Model, distributed by American Petroleum Institute), which requires information about the characteristics of the LNAPL and the related aquifer. Once the saturation profile $(S o)$ is obtained and the soil porosity $(\varphi)$ is known, the specific volume $(\mathrm{Vo})$ is given by [13]
TABLE 2: Soil input parameters in LDRM for specific volume estimation.

\begin{tabular}{lcc}
\hline & Sands & Sands and silty sands \\
\hline Porosity (-) & 0.25 & 0.20 \\
Hydraulic conductivity (m/d) & 6.43 & 1.05 \\
Van Genuchten $N(-)$ & 2.25 & 2.20 \\
Van Genuchten $\alpha(1 / \mathrm{m})$ & 2.60 & 3.20 \\
Irreducible water saturation $(\%)$ & 14.14 & 12.42 \\
\hline
\end{tabular}

$$
V o=\varphi \int_{0}^{\text {surf }} \operatorname{Sod} z
$$

LDRM directly provides the specific volume (as $D_{n}$ ) based on the input parameters, included porosity. In addition, this software provides also the specific recoverable volume $\left(R_{n}\right)$ due to the difference between the area subtended by the saturation LNAPL profile and that subtended by the residual saturation LNAPL profile [15].

In the case study LDRM has been adopted to derive the saturation profiles. The input parameters, as available, result from laboratory and field data as product thickness, ground surface elevation, water table elevation, LNAPL density (average value), and LNAPL viscosity (average value). Instead, because of limited availability of site-specific data, surface interfacial tensions, $N$ and $\alpha$ Van Genuchten parameters [16], porosity, hydraulic conductivity, and irreducible water saturation have been assumed from literature (Tables 1 and 2) [17, 37-39]. LDRM requires also the selection of a model (Burdine or Mualem) for LNAPL relative permeability determination. Burdine method for sands and Mualem method for sands and silty sands have been considered, because previous studies showed that the Burdine model, for fine materials, estimate relative permeability near to zero, not corresponding with real data $[15,18]$.

As in the Pancake Model, based on the specific volumes and the relative areas (Thiessen polygons and grid at regular square mesh) the total LNAPL volume was estimated. In this case, known $R_{n}$ (specific recoverable volume), also the total recoverable volume was calculated.

\section{Results}

The results of the calculation, using the Pancake Model, are about $9002 \mathrm{~m}^{3}$ for the Thiessen polygons, and about $8744 \mathrm{~m}^{3}$ and $4831 \mathrm{~m}^{3}$ for $200 \times 200$ and $100 \times 100$ grid at regular square mesh, respectively (Figure 5); instead, using the Thiessen 


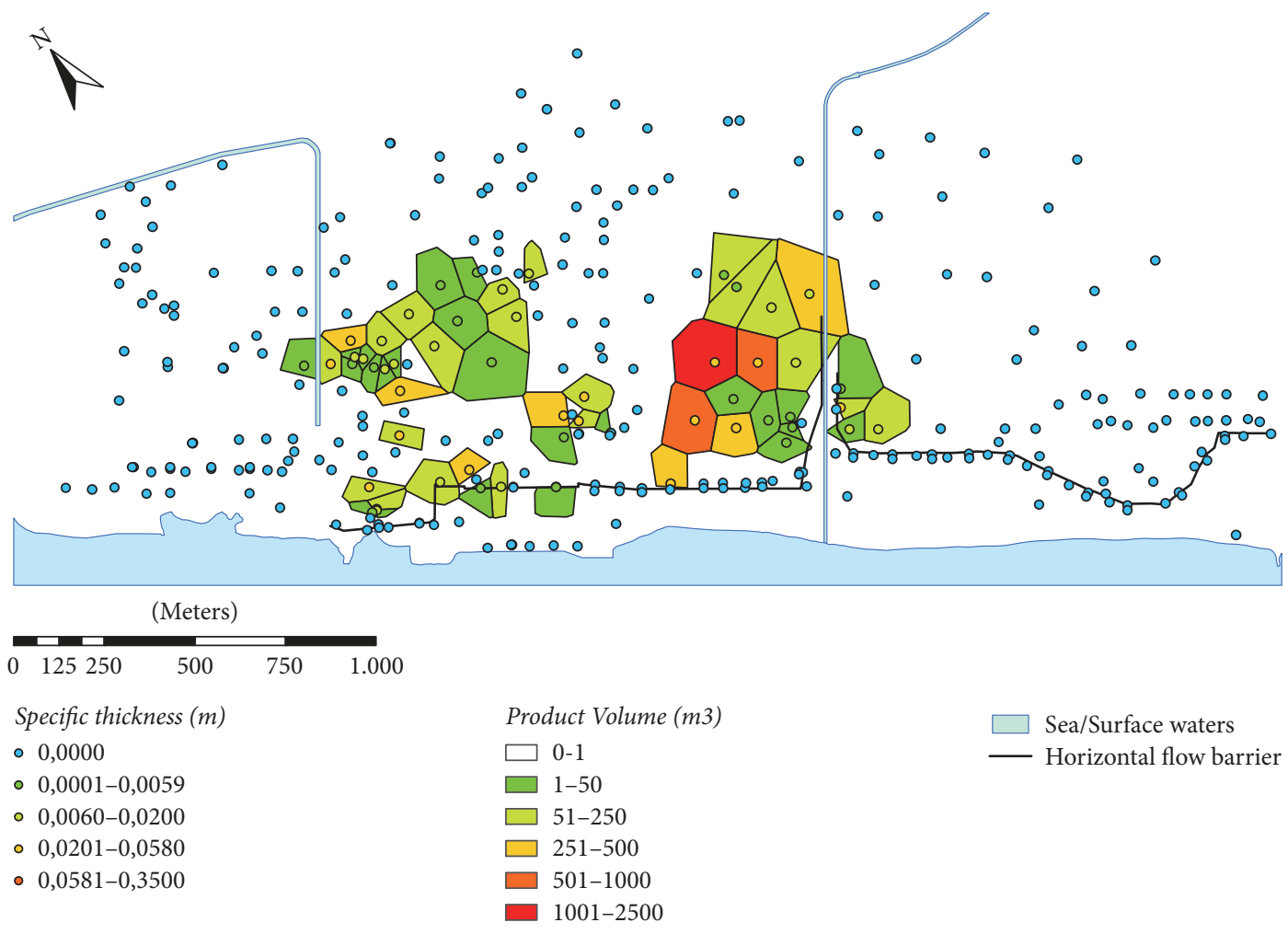

(a)

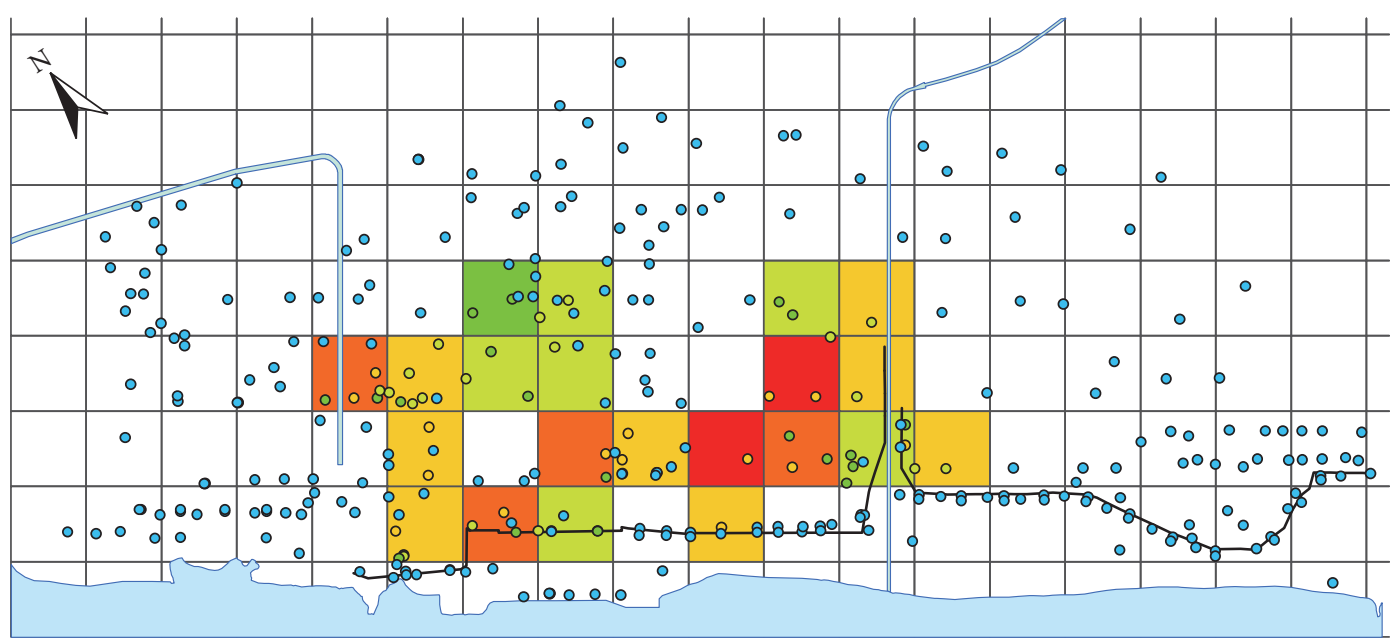

(Meters)

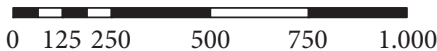

Specific thickness ( $m$ )

- 0,0000

Product Volume (m3)

- 0,0001-0,0059

- 0,0060-0,0200

- 0,0201-0,0580

$\square 0$-1

Sea/Surface waters

$\square 1-50$

Horizontal flow barrier

- 0,0581-0,3500

$\square$ 51-250

$\square$ 251-500

$\square$ 501-1000

1001-2500

(b)

Figure 5: Continued. 


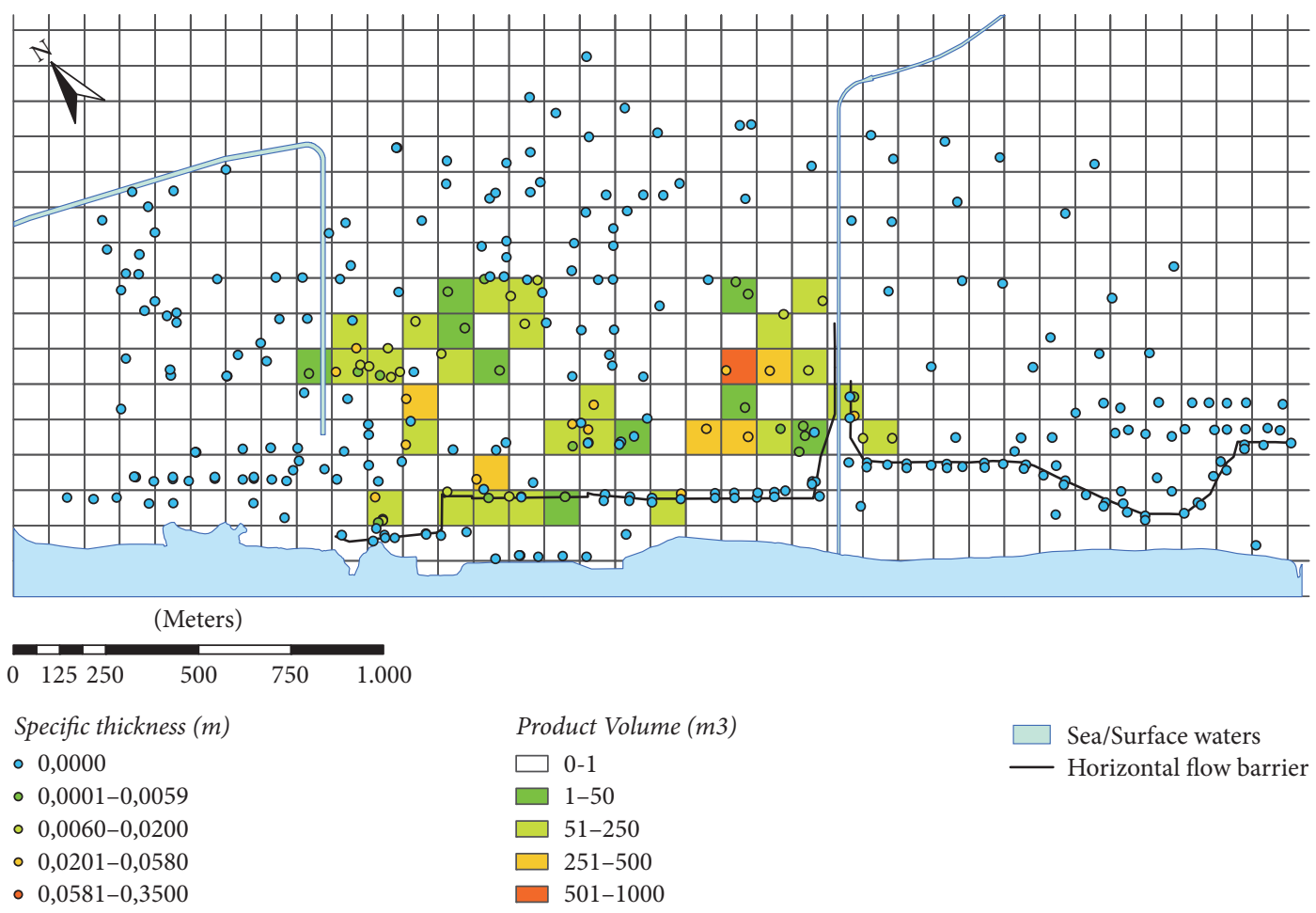

(c)

Figure 5: Product volume distribution in the study site at June 2013. The product volume was calculated using Pancake Model and Thiessen polygons $(\mathrm{a})$, grid at regular square mesh $(200 \times 200)(\mathrm{b})$, and grid at regular square mesh $(100 \times 100)(\mathrm{c})$.

polygons drawn considering both monitoring and pumping wells, the estimated volume is about $6856 \mathrm{~m}^{3}$.

The volume estimated applying the Vertical Equilibrium Model is about $5679 \mathrm{~m}^{3}, 4288 \mathrm{~m}^{3}$, and $3024 \mathrm{~m}^{3}$ for the Thiessen polygons, $200 \times 200$ and $100 \times 100$ grid at regular mesh, respectively (Figure 6). The recoverable volume calculation shows that about $70 \%$ of the product floating in the site can be removed by pumping (Figure 7), although in the field this amount can be reduced by several factors that influence the free LNAPL recovery such as well efficiency, well interference, and aquifer heterogeneity [40].

The comparisons between the results obtained using the two models and different methods to calculate areas show that there is a large difference between the estimated volumes that range from about $1810 \mathrm{~m}^{3}$ to $4460 \mathrm{~m}^{3}$ for $100 \times 100$ and 200 $\times 200$ regular mesh, respectively (Figure 8) [7]. In particular, the Vertical Equilibrium Model estimates lower volumes than the Pancake Model. In addition, it was found that for both models the estimated volume was higher for $200 \times 200$ regular mesh than for $100 \times 100$ regular mesh and Thiessen polygons. The difference between volumes estimated with the Pancake Model and the Vertical Equilibrium Model was about $51 \%$ using $200 \times 200$ mesh and about $37 \%$ using $100 \times$ 100 mesh and Thiessen polygons.

\section{Discussion and Limitations}

The significant differences observed between estimated volumes are due to different causes.
A first reason is due to the initial assumptions of both Pancake Model and Vertical Equilibrium Model. Indeed, the higher volumes estimated applying the Pancake Model is probably due to the overestimation of the LNAPL saturation considered in the two models (100\% in Pancake Model and less of $100 \%$ in Vertical Equilibrium Model). The assumption of a complete saturation represents a clear limitation of the Pancake Model because it ignores the critical influence of capillarity that controls LNAPL and water saturations, leading to a variability of saturation profiles in the subsurface $[19,33]$. In addition, the simple use of actual LNAPL thickness in the subsurface does not allow a correct estimation of LNAPL specific volume [19].

Another reason is the different evaluation methods for calculating the impacted area; indeed the differences observed between $200 \times 200$ and $100 \times 100$ mesh allow to affirm that the use of smaller mesh can lead to a reduction of these differences, but at this stage the available data do not permit using smaller mesh and confirm this theory. In fact, the $100 \times 100$ mesh is the most representative because the average distance between monitoring wells in the study site is about $95 \mathrm{~m}$. The adoption of the Thiessen polygons reveals another problem related to the construction method of these polygons. Indeed, since they are created as a function of the distance and spatial distribution of the monitoring wells, they have different shape and dimension affecting the volume calculation. Monitoring wells with similar specific volume can be associated with polygons with large differences in areas, leading to calculated volumes very different from point 


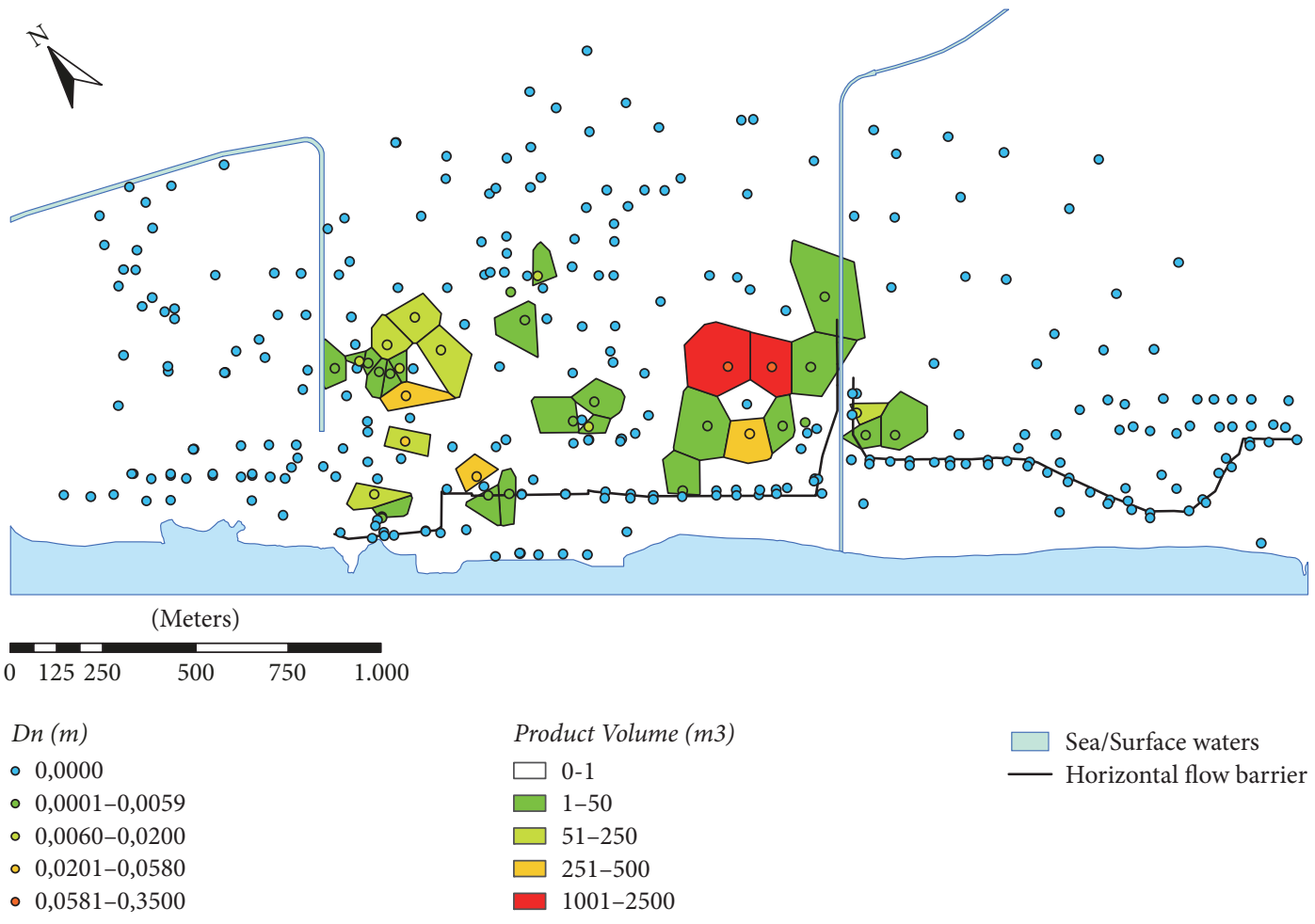

(a)

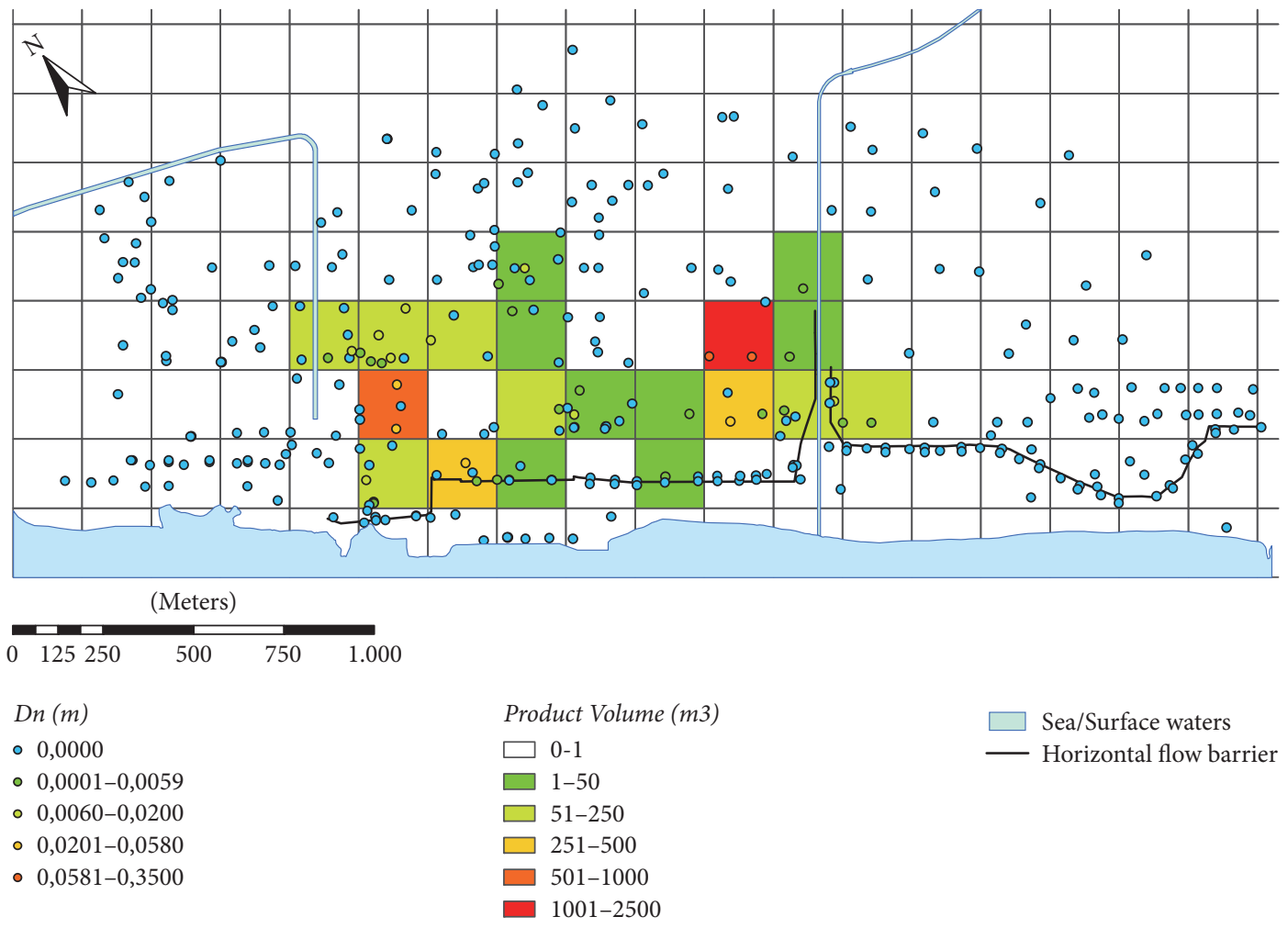

(b)

FIgURE 6: Continued. 


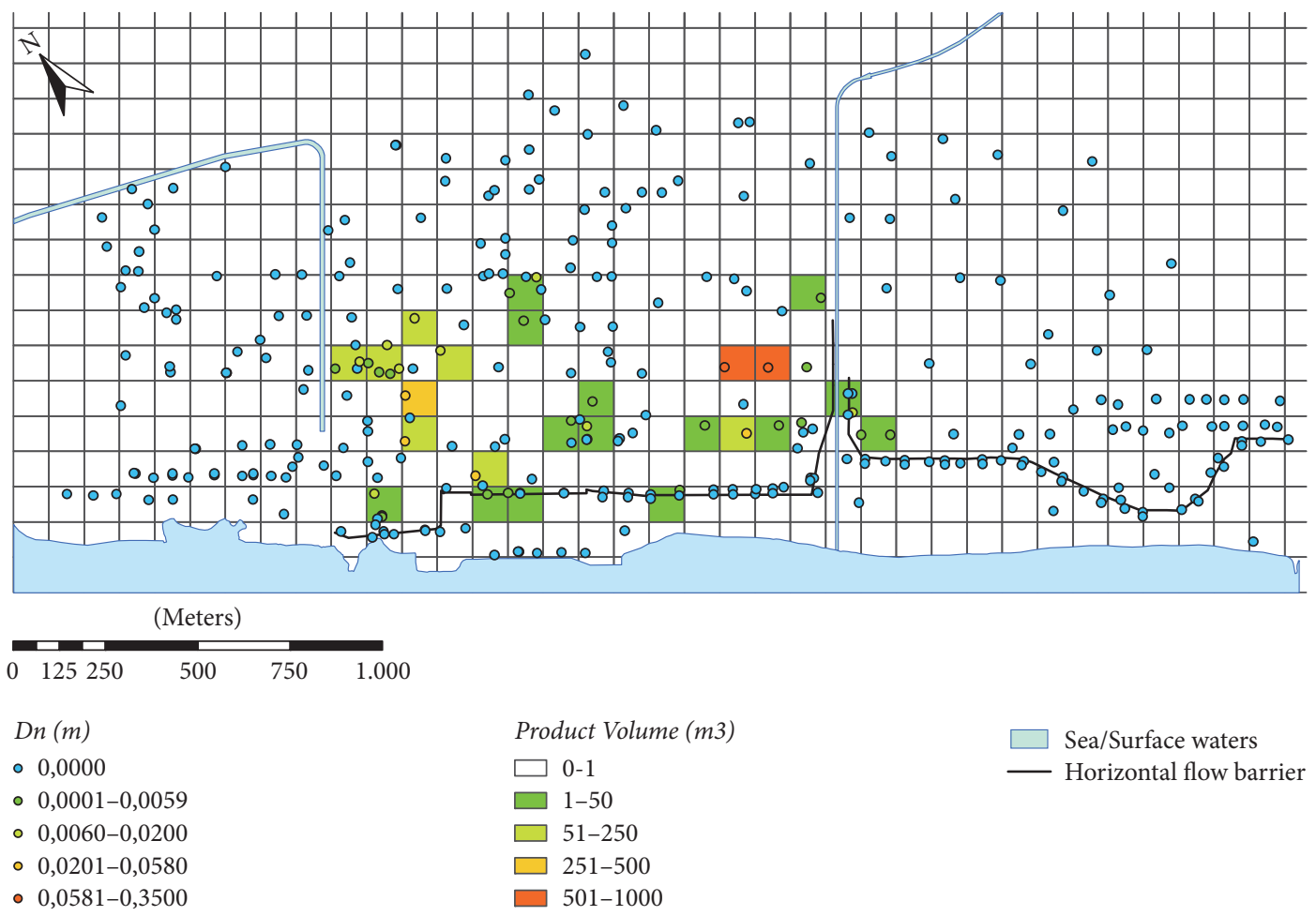

(c)

Figure 6: Product volume distribution in the study site at June 2013. The product volume was calculated using Vertical Equilibrium Model and Thiessen polygons (a), grid at regular square mesh $(200 \times 200)$, (b) and grid at regular square mesh $(100 \times 100)(c)$.

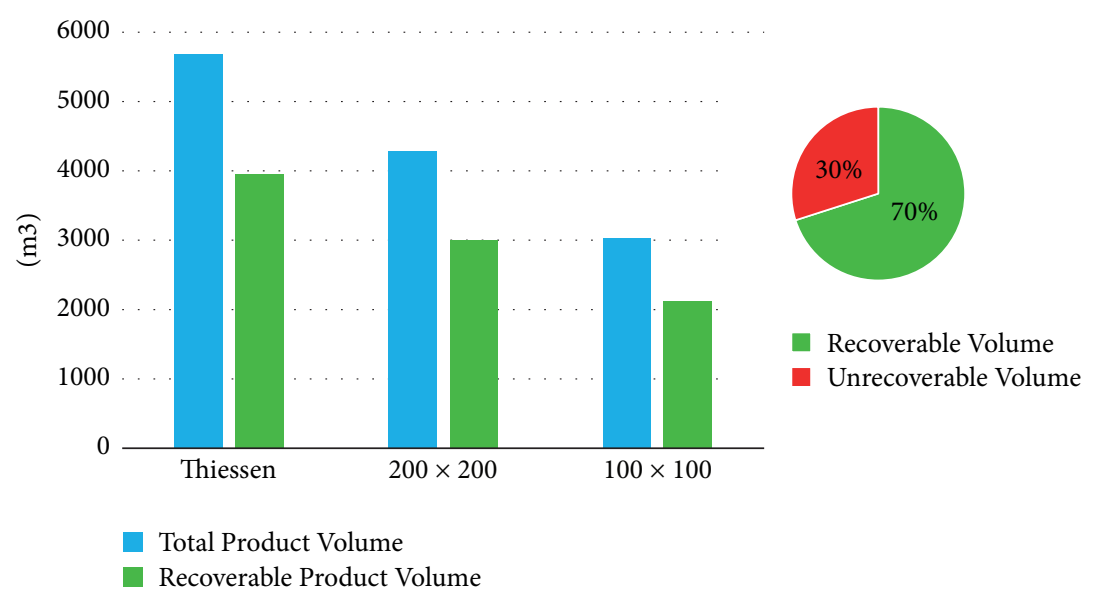

FIGURE 7: Comparison between total product volume and recoverable product volume of June 2013, estimated through the Vertical Equilibrium Model. The pie chart shows the recoverable volume and the unrecoverable volume through the pumping, according to the Vertical Equilibrium Model.

to point. The comparison of volumes obtained by the Pancake Model considering only the monitoring wells $\left(9002 \mathrm{~m}^{3}\right)$ and those obtained considering also the pumping wells $\left(6856 \mathrm{~m}^{3}\right)$ confirms the influence of the Thiessen polygons on the volume estimation.

In addition to the inaccuracy due to the area delimitation, caused also by the impossibility of using kriging because of high variability of LNAPL thickness and lack of homogeneous distribution, other critical points in the calculation of the LNAPL volume have been experienced. A first critical point, found both for Pancake Model and Vertical Equilibrium Model, is the measure of the product thickness in the wells during the monitoring surveys. This measurement can be affected by errors related to the necessary supernatant recovery carried out manually or automatically in monitoring wells. This action, if executed immediately before of the 


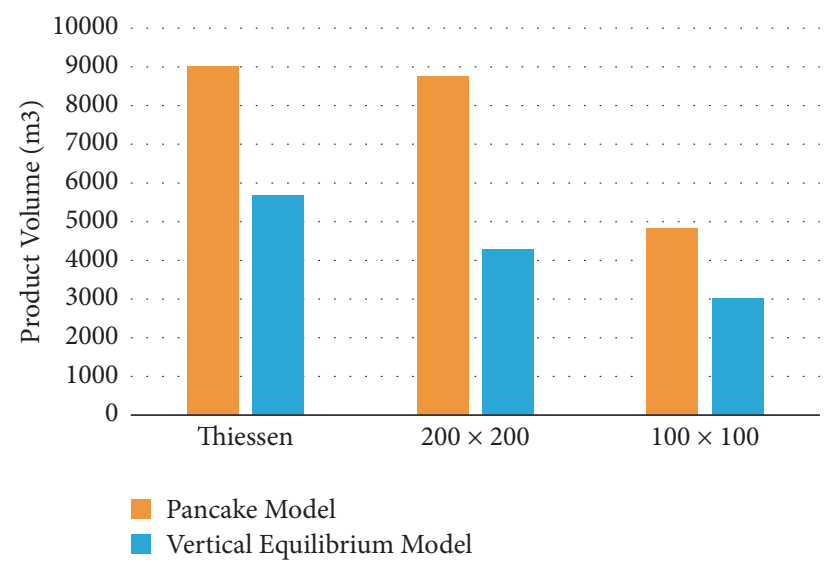

FIGURE 8: Comparison between product volumes estimated through Pancake Model and Vertical Equilibrium Model using Thiessen polygons and grid at square regular mesh $(100 \times 100,200 \times 200)$.

survey, can lead to measure underestimated thicknesses of the product. Another critical point is the existence, in the site, of different LNAPL compositions with different characteristics and behaviour. To limit this problem, as described in the previous paragraphs, different values of density, viscosity, surface tensions, and different exaggeration factors have been attributed at several monitoring points in function of the LNAPL type. In addition, the limited availability of some sitespecific data, such as porosity, can critically influence the volume estimation. The sensitivity analysis carried out for porosity, applying both Pancake Model and Vertical Equilibrium Model, shows that a reduction of effective porosity attributed to the two soils can produce a reduction of $20 \%$ of the estimated volume. In particular, applying an effective porosity of 0.20 for sands and of 0.15 for sands and silty sands, LDRM provides a reduction of about $22 \%$ of specific volumes for sands and of about $25 \%$ for sands and silty sands. Instead, the Pancake Model produces, applying the same effective porosities, $20 \%$ and $25 \%$ lower specific volumes, for sands and sands and silty sands, respectively. In Vertical Equilibrium Model, when monitoring wells are near pumping wells, the equilibrium conditions assumed by the model are not really reached on site, due to possible vertical gradient created by pumping, leading to an overestimation of real LNAPL thickness and so of the estimated volume. Both equilibrium conditions assumption and the requirement of many parameters influence the limitation of the Vertical Equilibrium Model. Indeed, as said above, these equilibrium conditions can be unreached and, in addition, information about vertical gradient is often not available. The requested insertion of values of many parameters requires so many additional monitoring activities and analyses that lead to a significant cost increase, often tackled using literature data instead of field data. Nevertheless, literature data have wide range and, as shown by sensitivity analysis for porosity, the choice of a value rather than another one greatly influences the volume estimation. In addition, some parameters (e.g., capillarity, interfacial tensions, and relative permeability) cannot be measured using field-scale testing, but they need to be estimated through modelling and lab-scale tests. The estimation through modelling results in nonunique solutions, while lab-scale testing presents unavoidable issue with potential scale applicability [41].

Finally, an additional limitation of Vertical Equilibrium Model is that its accuracy decreases for low permeability soils and heterogeneous soils and when there are significant water table fluctuations [33]. In detail, water table fluctuations influence the product volumes estimation because capillary pressure-saturation curves are nonunique and depend on whether there is drainage or wetting of LNAPL in the porous medium. In fact, a falling water table typically enhances the observed thickness of LNAPL in wells and consequently the mobile product volume estimation [33].

\section{Conclusion}

LNAPLs contamination is a key environmental issue due to the chemical-physical and toxicological characteristics of these contaminants. Indeed, their presence in the subsoil can have negative effects on human health and ecosystems; therefore, the remediation is fundamental to preserve them. In order to plan and achieve an efficient remediation of a polluted site, it is necessary to quantify the supernatant volume eventually floating on the water table. For this reason, two different existing conceptual models (Pancake Model and Vertical Equilibrium Model) have been applied for LNAPL volume estimation in the study site. The results show a remarkable difference (up to thousand cubic meters) between the volumes estimated through the two models, to be considered as a significant inaccuracy in method application. In particular, Pancake Model, having well-known limitations, estimates higher volumes with respect to Vertical Equilibrium Model, mainly due to their assumptions related to LNAPL saturation. Another difference in the volume estimation is linked to the extent of the areas associated with the monitoring wells; indeed, also in this case, a considerable difference of several cubic meters has been estimated. Additional critical points in the method application are (1) the measure of the product thickness in the wells during the monitoring campaigns, (2) the existence, in the site, of different LNAPL composition, and (3) the limited availability of some site-specific data, such as $\alpha$ and $N$ Van Genuchten parameters, irreducible water saturation, interfacial tensions, and porosity. Finally, a sensitivity analysis was performed on effective porosity, showing how lower values of this parameter reduce the estimated volume up to $20 \%$.

Based on the above, in order to reduce the inaccuracy due to the lack of site-specific data and to the nonhomogeneous distribution of monitoring points, in the future it is recommended to collect all necessary site-specific data and estimate again the free LNAPL volume through the two models. By this way, the influence of the adopted model will be definitely assessed. In other words, a comparison of the differences between the results derived by the two models needs to be performed in the future with more site-specific data, to reduce inaccuracy and conversely to definitely suggest the adoption of the most reliable of the models, taking into account also the benefit/cost ratio, linked to the needed investigations and analyses. 
At the current time, Vertical Equilibrium Model seems to be the most reliable, also using several literature data. This opinion is due to the more realistic assumption model according to which the LNAPL cannot float on the water table, but it can penetrate also under this dislocating water, and in the pore space it can be a coexistence of different fluids (LNAPL, water, and air). In addition, this model requires many parameters about LNAPL and soil characteristics and, nevertheless, this requirement leads to higher costs; it allows a more strict control on the influence of each considered parameter on the estimated LNAPL volume.

\section{Conflicts of Interest}

The authors declare that there are no conflicts of interest regarding the publication of this paper.

\section{Acknowledgments}

ENI and Italian Amec Foster Wheeler are acknowledged for providing data about the study site. Alessandro Lacchini and Valentina Marinelli (Department of Earth Sciences, University of Rome La Sapienza, Italy) are acknowledged for the study site data base design and management.

\section{References}

[1] E. R. Weiner, Applications of Environmental Chemistry: A Practical Guide for Environmental Professionals, CRC press LLC, Tampa, FL, USA, 2007, ISBN 978-0-8493-9066-1.

[2] K. Soga, J. W. E. Page, and T. H. Illangasekare, "A review of NAPL source zone remediation efficiency and the mass flux approach," Journal of Hazardous Materials, vol. 110, no. 1-3, pp. 13-27, 2004.

[3] M. Saleem, M. S. Al-Suwaiyan, S. A. Aiban, A. M. Ishaq, M. H. Al-Malack, and M. Hussain, "Estimation of spilled hydrocarbon volume - The state-of-the-art," Environmental Technology, vol. 25, no. 9, pp. 1077-1090, 2004.

[4] G. Baldi and M. Pacciani, "Acquiferi contaminati da idrocarburi: tecniche di quantificazione dell'inquinante. Prove in situ," Acque Sotterranee, vol. 55, pp. 21-36, 1997.

[5] E. J. Brost and G. E. DeVaull, "Non-aqueous phase liquid (NAPL) mobility in soil," Soil \& Goundwater Research Bullettin, vol. 9, 2000, American Petroleum Institute.

[6] CL:AIRE, An illustrated handbook of LNAPL transport and fate in the subsurface, CL:AIRE, London, UK, 2014, ISBN 978-1905046-24-9, http://www.claire.co.uk/LNAPL.

[7] E. Frollini and M. Petitta, "Volume estimation of free LNAPL in groundwater: comparison of Pancake Model and Vertical Equilibrium Model results and identification of critical points," in Proceedings of the 44th Annual Congress of the International Association of Hydrogeologists (IAH), "Groundwater Heritage and Sustainability”, Dubrovnik, Croatia, 2017, 2017, http://iah2017.org/.

[8] O. Iwakun, K. Biggar, and D. Sego, "Estimation of actual LNAPL thickness at a fuel-contaminated Arctic mine site," Cold Regions Science and Technology, vol. 60, no. 3, pp. 212-220, 2010.

[9] C. D. Johnston and M. G. Trefry, "Characteristics of light nonaqueous phase liquid recovery in the presence of fine-scale soil layering," Water Resources Research, vol. 45, no. 5, Article ID W05412, 2009.
[10] Los Angeles LNAPL Working Group, Light Non-Aqueous Phase Liquids (LNAPL) Literature Review Version 1.0, Western States Petroleum Association, Torrance, California, 2011, https:// www.gsi-net.com/en/publications/la-lnapl-recoverability-study/ source-report-a-literature-review/file.html.

[11] M. A. Dippenaar, M. D. Sole, J. L. Van Rooy, G. J. du Toit, and J. L. Reynecke, "Determining actual LNAPL plume thickness: Review and case study in a fractured aquifer," Bulletin of Engineering Geology and the Environment, vol. 64, no. 4, pp. 347-360, 2005.

[12] T. L. De Pastrovich, Y. Barthel, A. Chiarelli, and D. R. Fussell, "Protection of groundwater from oil pollution," Concawe 3/79, Concawe, The Hague, Netherlands, 1979.

[13] P. D. Lundegard and B. S. Mudford, "LNAPL volume calculation: Parameter estimation by nonlinear regression of saturation profiles," Groundwater Monitoring \& Remediation, vol. 18, no. 3, pp. 88-93, 1998.

[14] ITRC, "Evaluating LNAPL remedial technologies for achieving project goals. Interstate Technology and Regulatory Council, LNAPLs Team," 2009, http://www.itrcweb.org/guidance/ getdocument?documentid $=48$.

[15] API, "LNAPL Distribution and Recovery Model. Volume 1. Distribution and recovery of petroleum hydrocarbon liquids in porous media," API Publication Number 4760, American Petroleum Institute, Washington, DC, USA, 2007.

[16] API, "Methods for determining inputs to environmental petroleum hydrocarbon mobility and recovery models," API Publication Number 4711, American Petroleum Institute, Washington, DC, USA, 2001.

[17] API, "API Interactive LNAPL guide version 2.0.4," 2006, http:// www.api.org/oil-and-natural-gas/environment/clean-water/ ground-water/lnapl/interactive-guide.

[18] J. Jeong and R. J. Charbeneau, "An analytical model for predicting LNAPL distribution and recovery from multi-layered soils," Journal of Contaminant Hydrology, vol. 156, pp. 52-61, 2014.

[19] R. J. Lenhard, J. L. Rayner, and G. B. Davis, "A practical tool for estimating subsurface LNAPL distributions and transmissivity using current and historical fluid levels in groundwater wells: Effects of entrapped and residual LNAPL," Journal of Contaminant Hydrology, vol. 205, pp. 1-11, 2017.

[20] W. Jang, B. A. Anderson, R. J. Suárez-Soto, M. M. Aral, and M. L. Maslia, "Source Characterization and Simulation of the Migration of Light Nonaqueous Phase Liquids (LNAPLs) in the Vicinity of the Hadnot Point Industrial Area," in Analyses and Historical Reconstruction of Groundwater Flow, Contaminant Fate and Transport, and Distribution of Drinking Water Within the Service Areas of the Hadnot Point and Holcomb Boulevard Water Treatment Plants and Vicinities, U.S. Marine Corps Base Camp Lejeune, North Carolina-Chapter A: Summary and Findings. Atlanta, GA: Agency for Toxic Substances and Disease Registry, M. L. Maslia, R. J. Suárez-Soto, J. B. Sautner et al., Eds., 7, 2013.

[21] R. J. Lenhard, K. S. Lari, J. L. Rayner, and G. B. Davis, "Evaluating an analytical model to predict subsurface LNAPL distributions and transmissivity from current and historic fluid levels in groundwater wells: comparing results to numerical simulations," Groundwater Monitoring \& Remediation, 2018.

[22] A. Y. Pasha, L. Hu, and J. N. Meegoda, "Numerical simulations of a light nonaqueous phase liquid (LNAPL) movement in variably saturated soils with capillary hysteresis," Canadian Geotechnical Journal, vol. 51, no. 9, pp. 1046-1062, 2014. 
[23] K. Sookhak Lari, G. B. Davis, and C. D. Johnston, "Incorporating hysteresis in a multi-phase multi-component NAPL modelling framework; a multi-component LNAPL gasoline example," Advances in Water Resources, vol. 96, pp. 190-201, 2016.

[24] K. Sookhak Lari, C. D. Johnston, and G. B. Davis, "Gasoline multiphase and multicomponent partitioning in the vadose zone: Dynamics and risk longevity," Vadose Zone Journal, vol. 15, no. 3, 2016.

[25] K. Sookhak Lari, C. D. Johnston, J. L. Rayner, and G. B. Davis, "Field-scale multi-phase LNAPL remediation: Validating a new computational framework against sequential field pilot trials," Journal of Hazardous Materials, vol. 345, pp. 87-96, 2018.

[26] M. D. White, M. Oostrom, and R. J. Lenhard, "A practical model for mobile, residual, and entrapped NAPL in water-wet porous media," Groundwater, vol. 42, no. 5, pp. 734-746, 2004.

[27] M. Mastrocicco, N. Colombani, and M. Petitta, "Modelling the density contrast effect on a chlorinated hydrocarbon plume reaching the shore line," Water, Air, \& Soil Pollution, vol. 220, no. 1-4, pp. 387-398, 2011.

[28] M. Mastrocicco, N. Colombani, C. Sbarbati, and M. Petitta, "Assessing the effect of saltwater intrusion on petroleum hydrocarbons plumes via numerical modelling," Water, Air, \& Soil Pollution, vol. 223, no. 7, pp. 4417-4427, 2012.

[29] ANSR, "Diagnostic Gauge Plots. Simple yet powerful LCSM tools. Applied NAPL Science Review (ANSR), vol. 1, no. 2," 2011, http://www.h2altd.com/wp-content/uploads/2011/02/ANSR-vli2 .pdf.

[30] EPA, Detection and sampling of nonaqueous phase liquids in monitoring wells. FSOP 2.2.3 (March 8, 2011), Ohio EPA Division of Environmental Response and Revitalization http:// epa.ohio.gov/portals/30/rules/NAPL\%20Detection\%20\&\% 20Sampling,\%20FSOP\%202.2.3,\%203-8-11\%20FINAL.pdf.

[31] I. Kahraman, Analysis of a LNAPL recovery system using LDRM in a South Texas facility [Master of Science in Engineering Thesis], University of Texas at Austin, 2013, 2013, https://repositories .lib.utexas.edu/handle/2152/21796.

[32] LSPA, LNAPL and The Massachusetts Contingency Plan - Part I. LSP Association Technical Practice Committee, April 2005, http://www.lspa.org/assets/documents/wp-LNAPL-PartI040505 .pdf.

[33] SABCS (Science Advisory Board for Contaminated Sites, in British Columbia) Approaches and methods for evaluation of light non-aqueous. Hydrogeological assessment tools project. Report prepared by Golder Associates Ltd., February 2006, http://www.sabcs.chem.uvic.ca/LNAPL\%20Guidance\%200215-06\%20rev.pdf.

[34] T. S. Gruszczenski, "Determination of a realistic estimate of the actual formation product thickness using monitor wells: A field bailout test," in Proceedings of the Petroleum Hydrocarbons and Organic Chemicals in Ground Water, pp. 235-253, 1987.

[35] S. M. Testa and M. T. Paczkowski, "Volume Determination and Recoverability of Free Hydrocarbon," Groundwater Monitoring \& Remediation, vol. 9, no. 1, pp. 120-128, 1989.

[36] J. P. Hughes, C. R. Sullivan, and R. E. Zinner, "Two techniques for determining the true hydrocarbon thickness in an unconfined sandy aquifer," in Proceedings of the National Water Well Association of Ground Water Scientists and Engineers and the American Petroleum Institute Conference on Petroleum Hydrocarbons and Organic Chemicals in Ground Water: Prevention, Detection and Restoration, vol. 1, pp. 291-314, 1988.

[37] C. W. Fetter, Applied Hydrogeology, Prentice Hall, Inc, 4th edition, 2001.
[38] Kresic N., Hydrogeology and Groundwater Modeling, CRC Press, 2nd edition, 2006, ISBN 0849333482, 9780849333484.

[39] J. Šimůnek, M. Šejna, H. Saito, M. Sakai, and M. Th. Van Genuchten, "The HYDRUS-1D Software Package simulating the one-dimensional movement of water, heat, and multiple solutes in variably-saturated media," http://www.pc-progress.com/ Downloads/Pgm_hydrus1D/HYDRUS1D-4.08.pdf.

[40] API, "Evaluating hydrocarbon removal from source zones and its effect on dissolved plume longevity and magnitude," API Publication Number 4715, American Petroleum Institute, Washington, DC, USA, 2002.

[41] API, "LNAPL Distribution and Recovery Model (LDRM). Volume 2: User and parameter selection guide," API Publication Number 4760, American Petroleum Institute, Washington, DC, USA, 2007. 

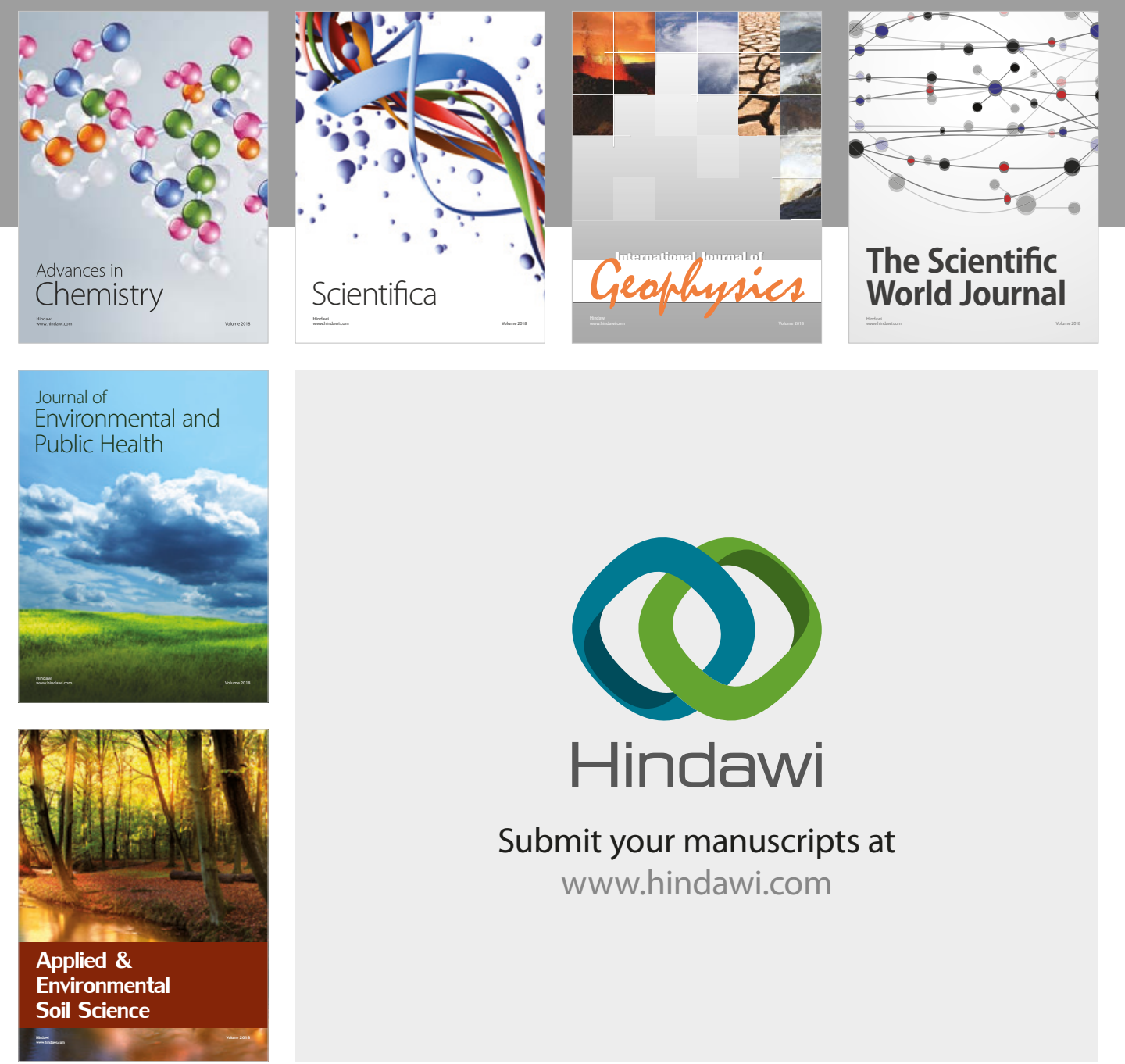

The Scientific

\section{World Journal}
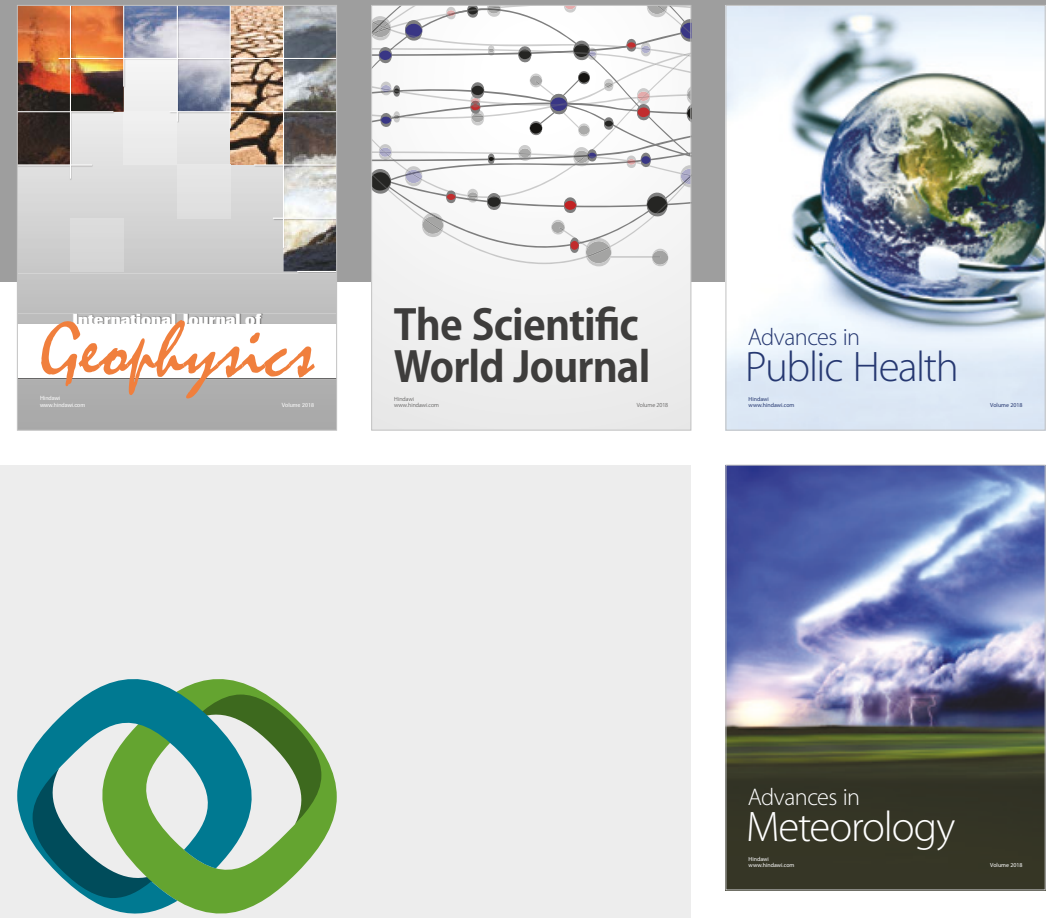

Advan

Public Health

\section{Hindawi}

Submit your manuscripts at

www.hindawi.com
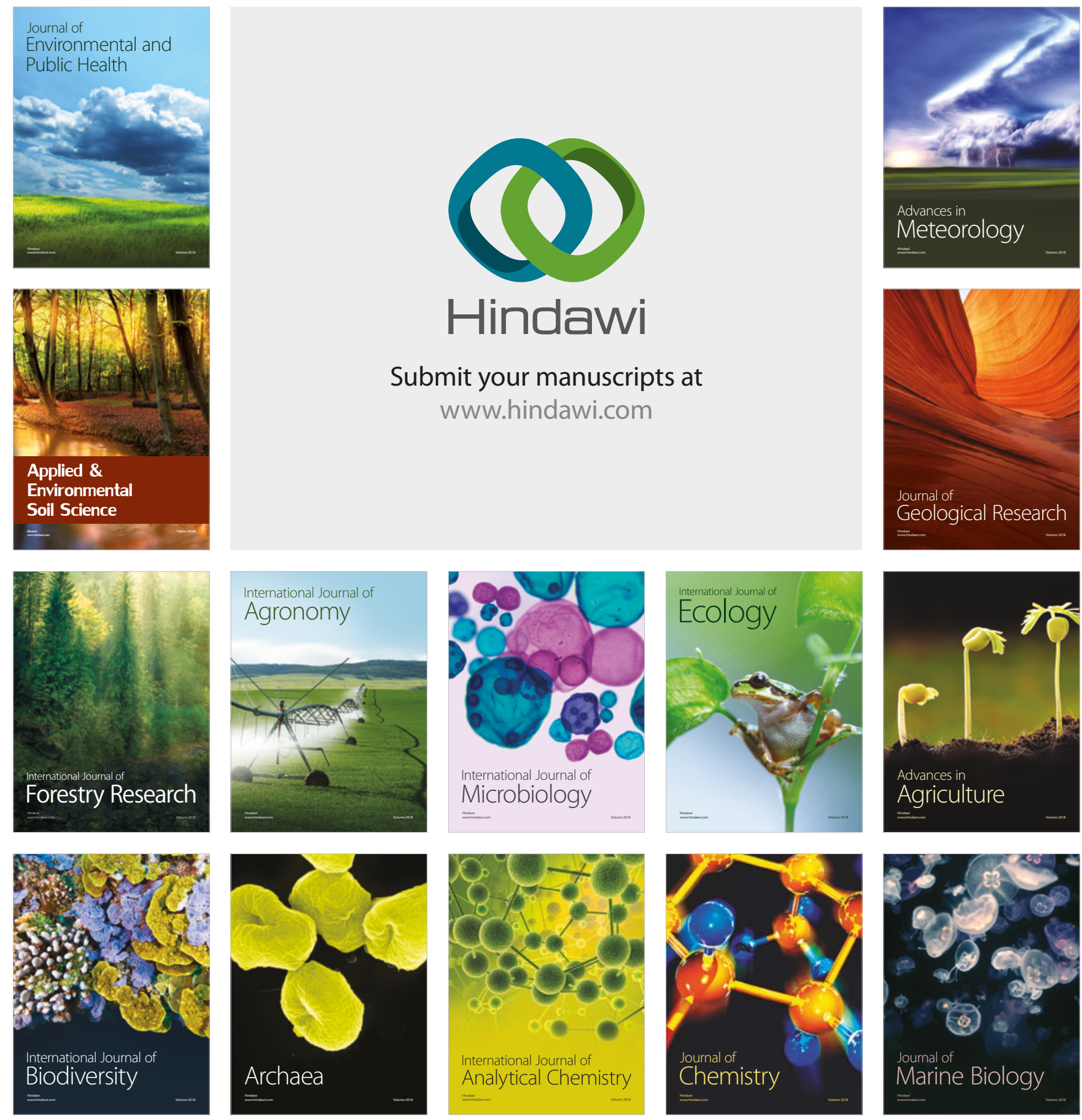